\title{
Retinopathy of Prematurity Stage 1 Demarcation Line
}

National Cancer Institute

\section{Source}

National Cancer Institute. Retinopathy of Prematurity Stage 1 Demarcation Line. NCI Thesaurus. Code C99047.

An ophthalmoscopic finding that refers to retinopathy of prematurity characterized by the presence of a faint demarcation line. 